\title{
Paradoxical embolization in an adult cystic fibrosis patient
}

\author{
Nabil M Al Lawati MD MRCP (UK), Pearce Wilcox MD FRCPC
}

\begin{abstract}
NM Al Lawati, P Wilcox. Paradoxical embolization in an adult cystic fibrosis patient. Can Respir J 2007;14(5):293-294.

Cystic fibrosis patients with an implantable venous access device (IVAD) and a patent foramen ovale (PFO) are at an increased risk of developing paradoxical embolism. A 33-year-old patient who had a cerebrovascular accident in the above setting is described. She had been anticoagulated because she had thrombosis of the tip of the indwelling catheter, and her PFO was closed percutaneuosly followed by replacement of her IVAD. She made a full neurological recovery. Echocardiography and prophylactic closure of the PFO, when present, as primary prevention for paradoxical embolism may be warranted in cystic fibrosis patients before placement of an IVAD.
\end{abstract}

Key Words: Cystic fibrosis; Paradoxical embolism; Patent foramen ovale

Cerebrovascular accident (CVA) in patients with cystic fibrosis $(\mathrm{CF})$ is a rare event. The occurrence of such an event should prompt the treating physician to look for an intracardiac lesion, such as a patent foramen ovale (PFO), which is a known risk factor for transient ischemic attack and stroke. We report the case of a 33-year-old woman who had a CVA secondary to paradoxical embolism through a PFO.

\section{CASE PRESENTATION}

A 33-year-old woman with CF, delta F508 homozygous, complicated by recurrent pulmonary exacerbations, diabetes mellitus, gastroesophageal reflux and pancreatic insufficiency presented with an abrupt onset of headache, diplopia, blurring of vision, temperature fluctuation and gait unsteadiness. Four days before presentation, she had developed intermittent fever and worsening of her long-standing cough. Further review of her past medical history revealed that she had had two transient episodes of visual disturbance over the past few years, for neither of which medical attention had been sought. She had a right-sided venous access device (Port-a-Cath, Smiths Medical MD Inc, USA) implanted 15 years earlier. There had been no overt problems with this access device and she did not have any family history of thrombophilia, stroke or cardiac conditions.

On clinical examination, the patient was alert, oriented, afebrile and breathing comfortably with peripheral oxygen saturation of $94 \%$ on $2 \mathrm{~L} / \mathrm{min}$ of oxygen. The site of the Port-aCath was unremarkable. She had clubbing, bilateral coarse

\section{Une embolisation paradoxale chez un patient adulte atteint de fibrose kystique}

\begin{abstract}
Les patients atteints de fibrose kystique munis d'un dispositif d'accès veineux implantable (DAVI) et d'un foramen ovale perméable (FOP) sont plus vulnérables à l'embolie paradoxale. On décrit le cas d'une patiente de 33 ans présentant ces caractéristiques et ayant souffert d'un accident vasculaire cérébral. On l'a traitée aux anticoagulants en raison d'une thrombose de l'extrémité de la sonde à demeure, on a fermé son FOP par voie percutanée, puis on a remplacé son DAVI. Elle a profité d'une récupération neurologique complète. Une échocardiographie et une fermeture prophylactique du FOP, s'il y a lieu, sont peut-être des mesures de prévention primaire justifiées chez les patients atteints de fibrose kystique avant l'installation d'un DAVI.
\end{abstract}

crackles on auscultation of the chest, and her heart sounds were normal with no murmurs or added sounds. An abdominal examination was normal.

Examination of the central nervous system had revealed a difficulty with short-term recall and no difficulty with longterm memory or attention. Her gait was slightly unsteady, with a tendency to veer to the right. In addition, the patient had slight difficulty with tandem gait, and swayed slightly on Romberg testing.

Tests for antiphospholipid antibody, factor $\mathrm{V}$ leiden and prothrombin gene mutation were all negative. An electrocardiogram was normal and an urgent computed tomography scan of the brain showed a $12 \mathrm{~mm}$ hypodensity in the medial aspect of the left thalamus that was in keeping with an infarction (Figure 1). An ultrasound Doppler study of the lower limbs showed no deep vein thrombosis. Angiography of the Port-a-Cath showed a patent catheter with a small thrombus adherent to the tip. An urgent echocardiogram with a bubble study showed valsalva- and cough-induced marked right to left shunt through a PFO. The cardiac chambers were normal in size, and the colour flow Doppler examination was normal. Pulmonary artery pressure could not be measured.

A diagnosis of paradoxical embolization was made in view of the above and the patient was started on anticoagulant therapy. Thrombolytic therapy was deferred because of the acute cerebrovascular accident. The patient showed significant improvement, both subjectively as well as objectively, over the next few days. Transesophageal echocardiogram 


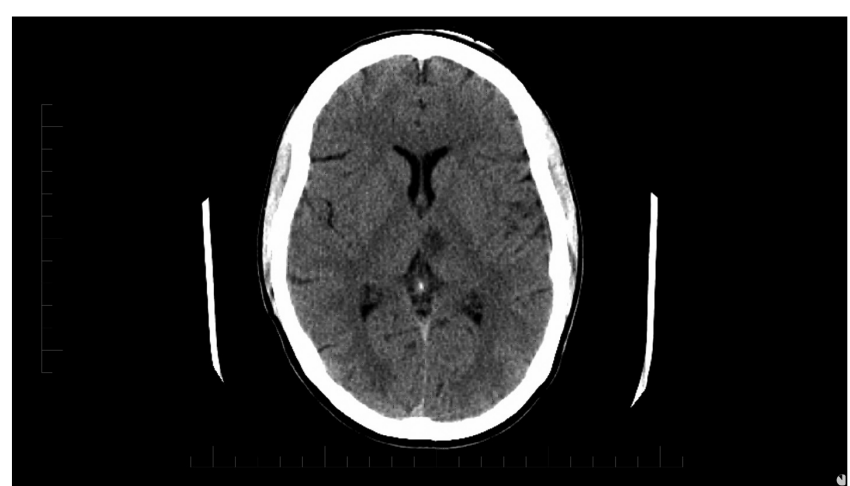

Figure 1) Left thalamic infarction

showed that the PFO was amenable to percutaneous closure. The patient underwent right-sided cardiac catheterization with PFO closure via a $25 \mathrm{~mm}$ Amplatzer PFO closure device. The implantable venous access device (IVAD) had been changed after the PFO closure. A repeat transesophageal echocardiogram after four months did not show any paradevice leak, with the device well seated across the atrial septum. The patient made a full recovery on neurological re-evaluation, and on a three-year follow-up, no new neurological events had transpired.

\section{DISCUSSION}

CVA in CF patients with IVADs in place should prompt the treating team to actively search for cardiac lesions, such as a $\mathrm{PFO}$, as a cause of paradoxical embolism. To date, there have been only three such reported cases in the literature (1-3).

$\mathrm{PFO}$ is a common cardiac lesion with a prevalence of $20 \%$ to $30 \%$ in the general population (4) and up to $36 \%$ in patients with cryptogenic stroke (5). It is an important risk factor for stroke and transient ischemic attack, with a stroke recurrence of $2.3 \%$ in patients with $\mathrm{PFO}(5)$. The prevalence of PFO is not well characterized in CF patients; however, it was reported to be the most prevalent echocardiographic abnormality in a group of adult CF patients (55\%) (6). Patients with $\mathrm{CF}$ are more prone to develop pulmonary hypertension secondary to lung disease and hypoxemia, with the potential for

\section{REFERENCES}

1. Playfor SD, Smyth AR. Paradoxical embolism in a boy with cystic fibrosis and a stroke. Thorax 1999;54:1139-40.

2. Espiritu JD, Kleinhenz ME. Paradoxical embolization in an adult patient with cystic fibrosis. Mayo Clin Proc 2000;75:1100-2.

3. Sritippayawan S, MacLaughlin EF, Woo MS. Acute neurological deficits in a young adult with cystic fibrosis. Pediatr Pulmonol 2003;35:147-51.

4. Hara H, Virmani R, Ladich E, et al. Patent foramen ovale: Current pathology, pathophysiology, and clinical status. J Am Coll Cardiol 2005;46:1768-76

5. Mas JL, Arquizan C, Lamy C, et al. Recurrent cerebrovascular events associated with patent foramen ovale, atrial septal aneurysm, or both. N Engl J Med 2001;345:1740-6.

6. Espiritu JD, Kleinhenz ME. Patent foramen ovale is the most prevalent echocardiographic abnormality in adult cystic fibrosis. Am J Respir Crit Care Med 2000;161:A71. (Abst) right to left shunt. The right-sided pressure can further increase with paroxysms of cough, such as the ones our patient had, increasing the risk of and/or worsening a right to left shunt.

While IVADs remain a convenient and relatively safe means of providing venous access for repeated antibiotic therapy in CF patients, there are a number of reported complications of these devices; the most common of these was thrombosis (40\%) (7). With such a finding and with the apparently high prevalence of $\mathrm{PFO}$, one should consider echocardiography on CF patients, especially those with severe disease, before placement of IVADs. Although controversial, prophylactic closure of $\mathrm{PFO}$, if present, in an attempt to prevent the potential complication of CVA secondary to a paradoxical embolism, may be justified. There is no evidence for routinely starting CF patients with IVADs on anticoagulant therapy. There are a number of case reports of mechanical embolization of catheter parts; however, we are aware of only a single case of pulmonary embolism secondary to catheter thrombosis in a CF patient (8). Hence, at this point, one cannot recommend routine prophylactic anticoagulation given that this is not a risk-free therapy.

Percutaneous transcathter device closure of $\mathrm{PFO}$ is the preferred means of closing PFO. It has been reported to be safe and effective, with efficacy ranging between $86 \%$ and $100 \%$ $(9,10)$. The Amplatzer device, such as the one used in our patient, had no thrombus formation compared with other devices in two reviews $(11,12)$.

\section{CONCLUSION}

$\mathrm{PFO}$ is a common cardiac lesion which is apparently a common echocardiographic finding in CF patients. It is an important risk factor for transient ischemic attack and stroke secondary to paradoxical embolism, especially with indwelling venous access devices. Prophylactic closure as the primary prevention for CVA may be warranted in CF patients before placement of IVADs.

ACKNOWLEDGEMENTS: The authors of this study, Drs Nabil M Al Lawati and Pearce Wilcox, have no conflicts of interest or financial disclosures.

7. Aitken ML, Tonelli MR. Complications of indwelling catheters in cystic fibrosis: A 10-year review. Chest 2000;118:1598-602.

8. Yung B, Elborn JS, Campbell IA, Summers Y, Beckles M, Woodcock AA. Thromboembolism related to a Port-a-Cath device in a patient with cystic fibrosis. Thorax 1997;52:98-9.

9. Martin F, Sanchez PL, Doherty E, et al. Percutaneous transcatheter closure of patent foramen ovale in patients with paradoxical embolism. Circulation 2002;106:1121-6.

10. Meier B. Closure of patent foramen ovale: Technique, pitfalls, complications, and follow up. Heart 2005;91:444-8.

11. Krumsdorf U, Ostermayer S, Billinger K, et al. Incidence and clinical course of thrombus formation on atrial septal defect and patent foramen ovale closure devices in 1,000 consecutive patients. J Am Coll Cardiol 2004;43:302-9.

12. Anzai H, Child J, Natterson B, et al. Incidence of thrombus formation on the CardioSEAL and the Amplatzer interatrial closure devices. Am J Cardiol 2004;93:426-31. 


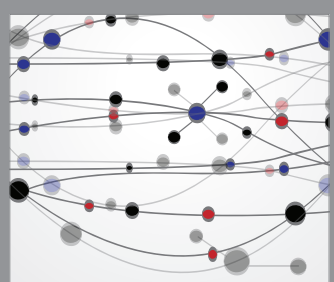

The Scientific World Journal
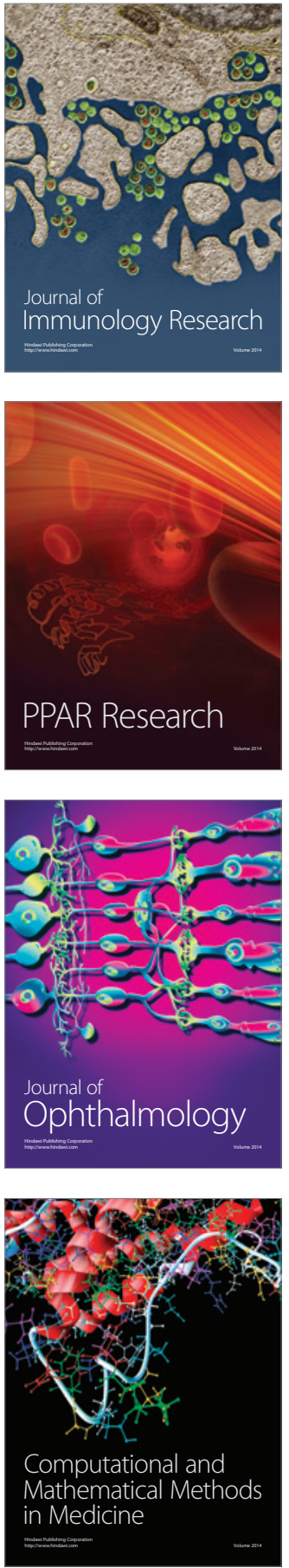

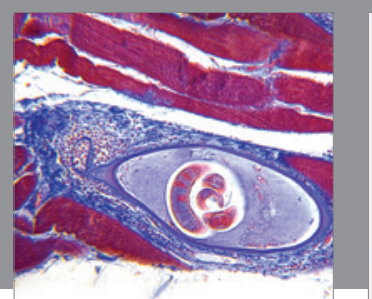

Gastroenterology Research and Practice

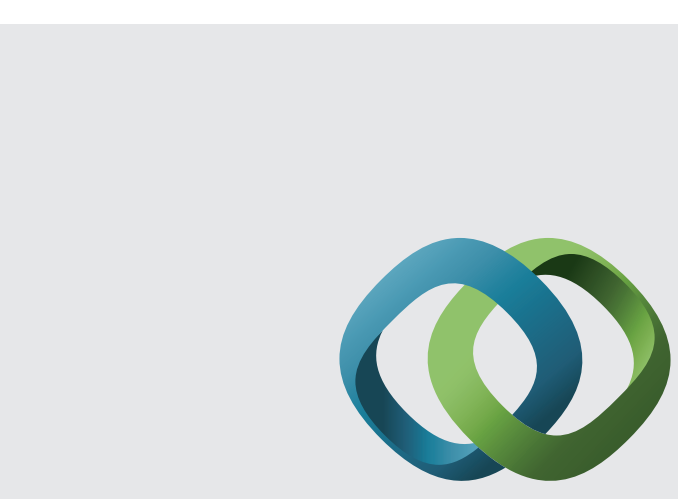

\section{Hindawi}

Submit your manuscripts at

http://www.hindawi.com
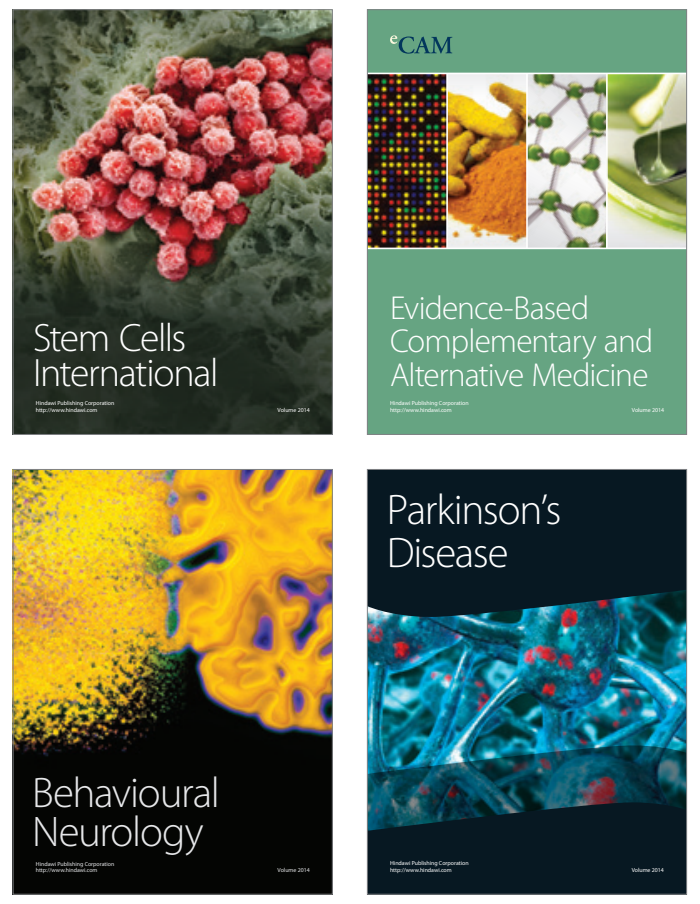
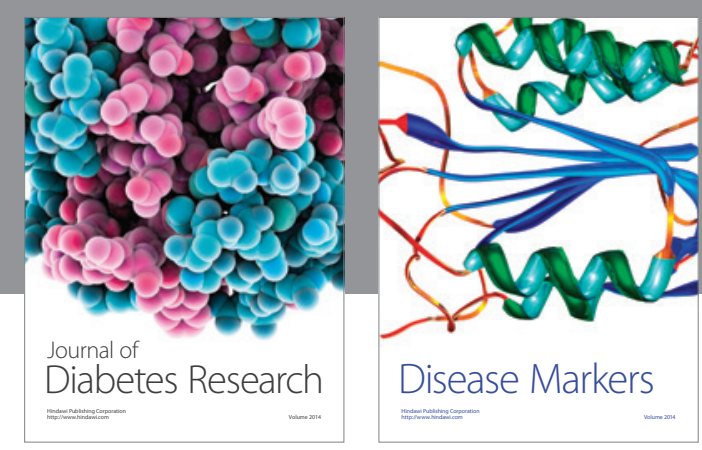

Disease Markers
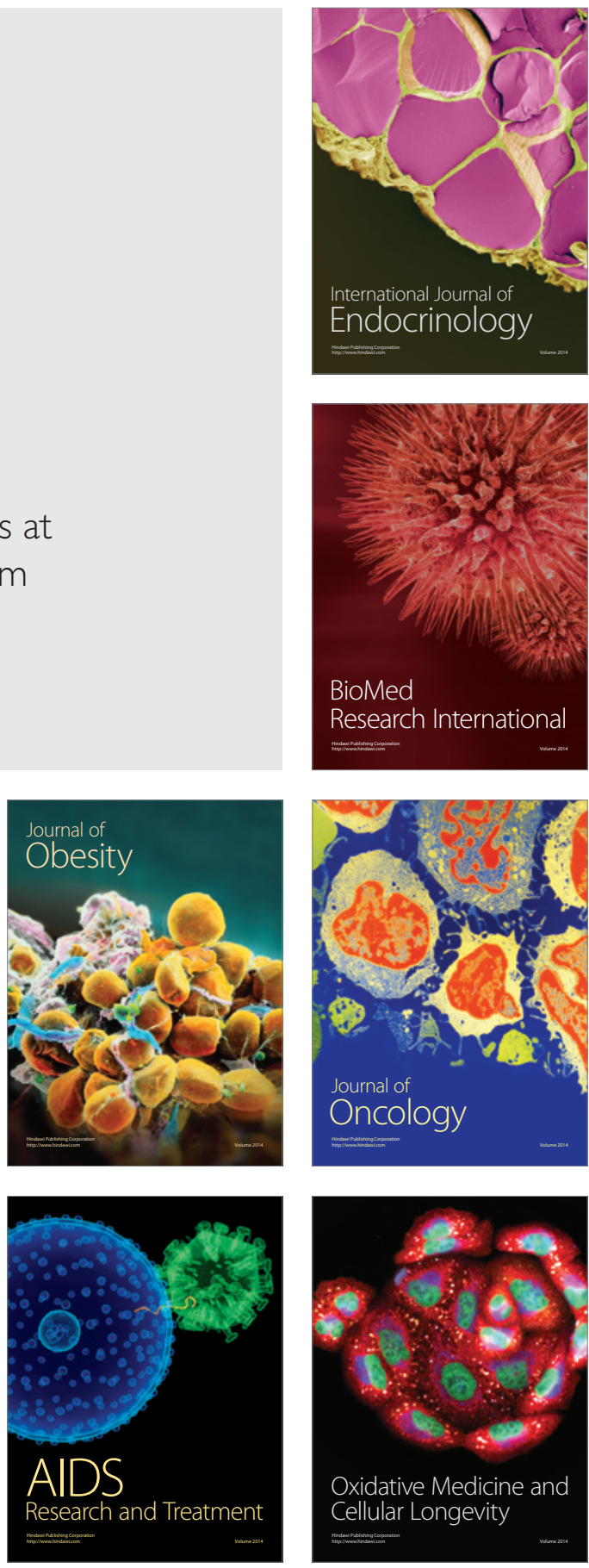